\title{
Vertical Handover Decision Algorithm Using Multicriteria Metrics in Heterogeneous Wireless Network
}

\author{
Gita Mahardhika, Mahamod Ismail, and Rosdiadee Nordin \\ Department of Electrical, Electronics and System, Faculty of Engineering and Built Environment, Universiti Kebangsaan Malaysia, \\ 43000 Bangi, Malaysia
}

Correspondence should be addressed to Gita Mahardhika; gita@eng.ukm.my

Received 27 July 2014; Revised 25 November 2014; Accepted 25 November 2014

Academic Editor: Rui Zhang

Copyright (C) 2015 Gita Mahardhika et al. This is an open access article distributed under the Creative Commons Attribution License, which permits unrestricted use, distribution, and reproduction in any medium, provided the original work is properly cited.

\begin{abstract}
Heterogeneous network concept was introduced to satisfy the demands of network's traffic capacity and data rate. It consists of multiplatform networks with various radio access technologies. Conventionally, a mobile user may roam and accomplish the vertical handover using single criteria, such as received signal strength (RSS). Single criteria vertical handover decision, however, may cause inefficient handoff, unbalanced network load, and service interruption. This paper proposed an improved vertical handover decision using multicriteria metrics in the environment of heterogeneous network consisting of three network interfaces: (i) wireless local area network (WLAN), (ii) wideband code division multiple access (WCDMA), and (iii) worldwide interoperability for microwave access (WiMAX). In the vertical handover decision, four metrics are considered: (i) RSS, (ii) mobile speed, (iii) traffic class, and (iv) network occupancy. There are three types of the vertical handover decision algorithm: (i) equal priority, (ii) mobile priority, and (iii) network priority. Equal priority multicriteria handover algorithm improved the number of handoffs by 46.60 while mobile priority multicriteria algorithm improved the number of handoffs by $90.41 \%$ and improved the balance index by $0.09 \%$. Network priority multicriteria method improved the number of handoffs by $84.60 \%$, balance index by $18.03 \%$, and average blocking probability by $20.23 \%$.
\end{abstract}

\section{Introduction}

The demand of data rate and traffic capacity of mobile communication is growing rapidly; thus the concept of heterogeneous network is introduced to meet this demand. In a heterogeneous network, mobility feature is essential because mobile stations must be able to roam throughout the network and able to connect to various radio access technologies (RATs). Conventionally, mobile station considers the point of attachment (PoA) based on single criteria such as received signal strength (RSS).

The method to decide handover based on RSS is considered as the simplest method to decide handover [1] but, on the other hand, it may not have sufficient reliability because of the RSS fluctuation [2]. Each network involved in heterogeneous network has different threshold of RSS; thus the RSS-based method leads to inefficient handoff, unbalanced load, and service interruption.
There are issues to be addressed in vertical handover decision. First, the algorithm should have the reliability as inaccurate vertical handover decision may cost the excessive usage of network resource. Second, the algorithm should have the function as a network balancer. The vertical handover decision algorithm should provide accuracy to balance the traffic load for all involved networks. Third, the algorithm should be accurate that it may reduce the network blocking probability.

Multicriteria decision making is an appropriate method for vertical handover decision because there is more than one target network as the decision alternatives. Furthermore, multicriteria decision making provides flexibility to consider several criteria to decide the best network.

\section{Related Works}

There are several methods of vertical handover decision algorithm. Generally, it may be classified into five categories: 
(i) RSS-based, (ii) multicriteria, (iii) context-aware, (iv) cost function, and (v) fuzzy logic. RSS-based method is a conventional handover decision algorithm which uses RSS as the handover trigger [3] and as the main criteria to decide handover [4]. RSS-based method has been optimized by adapting RSS threshold [5] and by combining RSS threshold with user's velocity and location [6]. Context-aware strategies use the signal quality and the context of the mobile user and the network to decide handover [7]. There is a broad definition of context. It may be defined as any information that can be used to characterize the situation of an entity [8], or it may be a location, environment, identity, and time [9].

There are two approaches in cost function strategy: network-related cost function and user-related cost function [10]. Time unit, monetary cost, and user bit rate are several metrics involved in user-related cost function $[11,12]$. In fuzzy logic strategy, there are two steps of the procedure: the fuzzification and weighting procedure and the decision making [13]. In decision making, fuzzy logic method may use MADM (multiattributes decision making) [14] or multicriteria method [15]. By combining multicriteria method, the handover decision algorithm achieved lower power consumption [16].

In most cases, RSS-based method has the lowest complexity compared to other methods, even though the accuracy of RSS-based method may be the least. On the contrary, high complexity methods such as fuzzy logic and cost function provide higher accuracy and network efficiency.

There are extensive works on multicriteria vertical handover decision algorithm. Multicriteria method has an ability to make quantitative calculation on decision using several criteria between several candidates [13]. The methods of multiplicative exponent weighting (MEW), simple additive weighting (SAW), technique for order preference by similarity to ideal solution (TOPSIS), and grey relational analysis (GRA) [17] are compared and their performance (in terms of handover delay) is evaluated [18]. The comparison was simulated in the heterogeneous network environment of WLAN, UMTS, and GPRS. Network performance (BER, delay, jitter, and bandwidth) was compared.

There is also a comparison and performance evaluation between SAW and weighted product model (WPM) in terms of processing delay [19] in the environment of WLAN and WiMAX. The results indicated that WPM has better accuracy in choosing target network compared to SAW. Another multicriteria method, ELECTRE, has been implemented as vertical handover decision and evaluated using numerical analysis. ELECTRE (Elimination et Croix Traduisant la Realite or elimination and choice expressing reality) is compared to the method of SAW and TOPSIS [20]. In multicriteria vertical handover decision, the chosen criteria have to be appropriate to ensure the accuracy of the decision. There are many criteria, user-related or networkrelated, such as RSS, mobility, application, and bandwidth.

\section{Simulation Methodology}

To obtain performance results, proposed method is implemented using MATLAB simulation. There are four stages

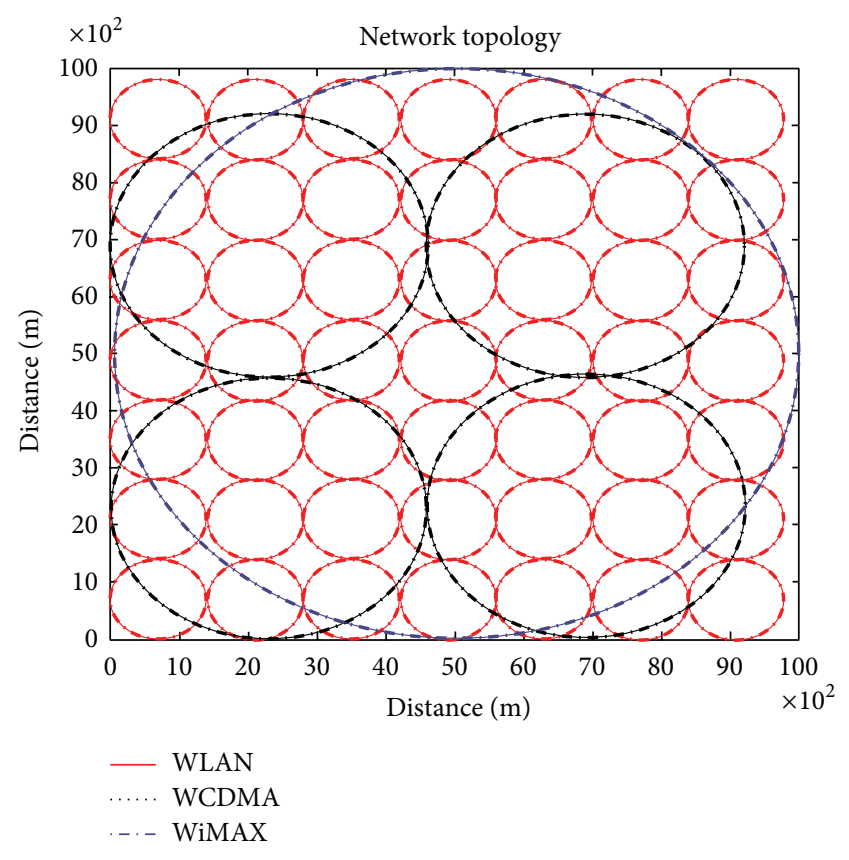

FIGURE 1: Network topology.

of the simulation: (i) modelling of heterogeneous network, (ii) multicriteria vertical handover decision, (iii) implementation of TOPSIS multicriteria decision making into the heterogeneous network environment, and (iv) performance evaluation of the network. In the first stage, heterogeneous network topology base station parameters and mobile station parameters are defined. In the second stage, multicriteria vertical handover decision based on the technique for order preferences by similarity to an ideal solution (TOPSIS) is proposed. In the third stage, proposed algorithm is implemented in heterogeneous network environment. In the fourth stage, the network performance is measured in terms of number of handoffs, balance index, and average blocking probability.

3.1. Heterogeneous Network. In this study, heterogeneous network consists of WLAN, WCDMA, and WiMAX, as illustrated in Figure 1. The cell radius of WLAN is $700 \mathrm{~m}$, WCDMA $2.3 \mathrm{~km}$, and WiMAX $5 \mathrm{~km}$. WLAN covers $78.54 \%$ of the simulation area; meanwhile WCDMA covers $66.48 \%$ and WiMAX covers $75.43 \%$. Base stations parameter is presented in Table 2.

There are different propagation models for each type of network (WLAN, WCDMA, and WiMAX). For WiMAX network, empirical WiMAX propagation model is used to calculate the coverage dimensioning:

$$
A=A o+10 \gamma \log \left(\frac{d}{d o}\right)
$$

Ao is $105.45 \mathrm{~dB}$ measured at $d o=200 \mathrm{~m}$. Path loss exponent, $\gamma$, is 3.911. Lower value of path loss exponent represents the more line of sight (LoS) propagation. 
In WCDMA network, the network propagation model follows COST 231 Walfish-Ikegami model as it is a standard model for 3G IMT 2000/UMTS [25]:

$$
L=42.6+26 \log (d)+20 \log (f)
$$

where $d$ is distance from base station to mobile user in $\mathrm{km}$ and $f$ is operating frequency in $\mathrm{MHz}$.

Empirical one-slope model is used as the propagation model for WLAN [26] with formula as follows:

$$
L(d)=L o+10 \gamma \log (d)
$$

where Lo is reference loss value for the distance of $1 \mathrm{~m}, \gamma$ is path loss exponent, and $d$ is distance in meters. For operating frequency $2.45 \mathrm{GHz}$, Lo is $40 \mathrm{~dB}$ and $\gamma$ is 3.5 [26].

There are two mobile station parameters in this study: speed and traffic type. There are 4 (four) speed classes: (i) stationary mobile stations, (ii) pedestrian mobile stations, (iii) low speed vehicular mobile stations, and (iv) high speed vehicular mobile stations. Pedestrian mobile station has the speed of $1.3 \mathrm{~m} / \mathrm{s}$, low speed vehicular mobile station of $3 \mathrm{~m} / \mathrm{s}$, and high speed vehicular mobile station of $4.7 \mathrm{~m} / \mathrm{s}$ [27].

There are 3 (three) traffic classes: (i) conventional service, (ii) streaming service, and (iii) best effort service. Conventional service has a low delay but may be compromised in bit error rate. Streaming service has average quality in both delay and bit error rate. Best effort service has low bit error rate without concern in delay. Bit rate for conventional service is $32 \mathrm{kbps}$, streaming service $512 \mathrm{kbps}$, and best effort service $128 \mathrm{kbps}$ for best effort service [8].

3.2. TOPSIS Multicriteria Decision Making. Compared to other multicriteria methods, the technique for order preferences by similarity to an ideal solution (TOPSIS) has several advantages. It has conceptual simplicity and good computational efficiency and it has the ability to measure relative performance for each alternative [15]. TOPSIS only requires one subjective input, the weightage, to calculate the decision. In simulation, TOPSIS provides higher throughput and lower packet loss compared to other multicriteria decision making methods [20].

\subsection{Multicriteria Vertical Handover Decision Algorithm.} There are 4 (four) criteria involved in the handover decision algorithm. Those are RSSI, traffic class, speed, and network occupancy. Input parameters of the algorithm are base stations parameters (network topology and radio parameters) and mobile stations parameters (speed class and traffic type). The flowchart of the algorithm is presented in Figure 2.

TOPSIS method provides flexibility in defining the weightage of the multicriteria priority. There are three types of priority in multicriteria vertical handover decision: (i) equal priority, (ii) mobile priority, and (iii) network priority. Mobile priority method emphasizes mobile parameter (speed class and traffic type); meanwhile network priority emphasizes network occupancy. Each priority has a certain weightage as presented in Table 3.
3.4. Performance Measurement. There are three performance parameters: (i) number of handoffs, (ii) balance index, and (iii) average blocking probability (Figure 11). Number of handoffs is a total vertical handover occurrence during active call. Number of handoffs is an essential performance parameter in the mobile network because it is correlated with the signalling load and delivered QoS. Handover execution requires certain amount of network resources; thus unnecessary handover may cause inefficiency.

Load balance is also essential as unbalanced load may cause congestion in one network while excess network resources in other networks are unused [28]. By creating a balanced network, more mobile users may be served and the network will have a higher throughput and lower packet delay [29]. The value of balance index represents the network balance, where the imbalance of the network is greater with the higher balance index value. There is no unit of balance index, and the formulation is presented in (4). Load network is the network throughput in bps:

$$
\begin{gathered}
B=\left(\text { }_{\text {load }} \text { WLAN-WCDMA }+\Delta \text { load }_{\text {WLAN-WiMAX }}\right. \\
\left.+\Delta \text { load }_{\text {WCDMA-WiMAX }}\right) \times(3)^{-1} \\
\Delta \operatorname{load}_{\text {WLAN-WCDMA }}=\left|\operatorname{load}_{\text {WLAN }}-\operatorname{load}_{\text {WCDMA }}\right| \\
\Delta \text { load }_{\text {WLAN-WiMAX }}=\left|\operatorname{load}_{\text {WLAN }}-\operatorname{load}_{\text {WiMAX }}\right| \\
\Delta \operatorname{load}_{\text {WCDMA-WiMAX }}=\left|\operatorname{load}_{\text {WCDMA }}-\operatorname{load}_{\text {WiMAX }}\right| .
\end{gathered}
$$

Blocking probability model in this study follows Erlang B model, with $M / M / c$ queuing model with multiserver. The call arrival model follows Poisson process, with limited server number $c$. Erlang B blocking probability complies with lost call cleared model (Erlang loss model) where blocked calls are immediately abandoned [30]. Average blocking probability represents the blocking probability for the heterogeneous network which consists of three types of network, WLAN, WCDMA, and WiMAX.

\section{Results and Discussions}

There are three types of priority in multicriteria vertical handover decision algorithm: equal priority, mobile priority, and network priority, implemented in heterogeneous network environment (Table 1). The performance of each type of priority is measured and compared to the conventional method. Conventional method uses RSSI as single criteria; meanwhile multicriteria method considers traffic class, speed, and network occupancy.

Figure 3 presents the number of handoff distributions of equal priority multicriteria, for 1800 simulation time and 200 mobile users. Equal priority multicriteria method has reduced the number of handoffs by $46.60 \%$. Using conventional method, the mean of number of handoffs is 85 and decreased to 46 after the implementation of equal priority multicriteria. Number of handoffs has significantly decreased so the network efficiency is improved and extra resource of the network is available for other usage. 


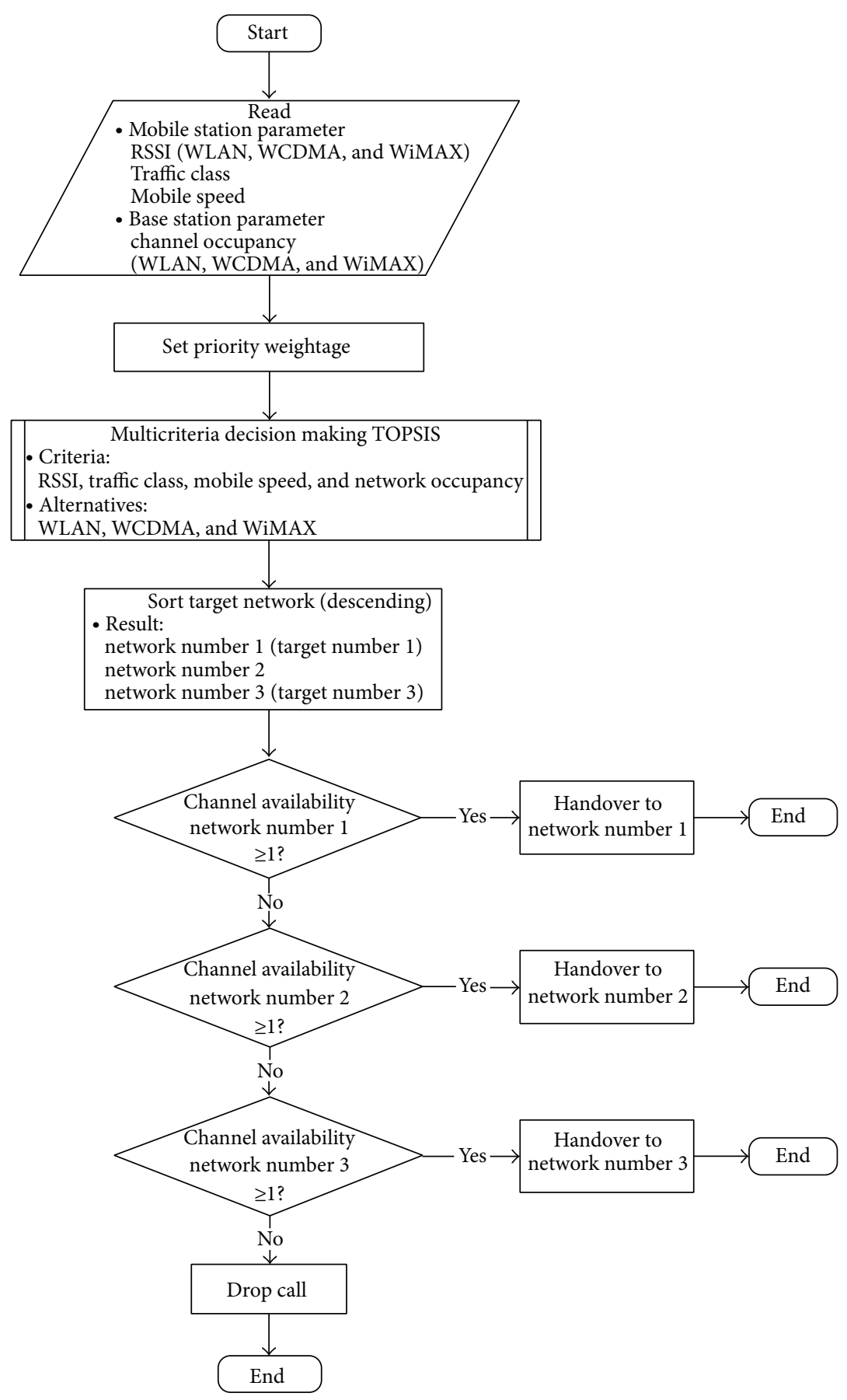

FIGURE 2: Multicriteria vertical handover decision algorithm.

Figure 4 presents the distribution function of number of handoffs after the implementation of mobile priority multicriteria. Mobile priority multicriteria reduced number of handoffs by $90.41 \%$. Number of handoff means by using conventional method is 63 , and the implementation of mobile priority multicriteria has successfully dropped the number to 6.

Number of handoffs for network priority multicriteria is presented in Figure 5. The improvement is $84.60 \%$, where number of handoff means for conventional method is 67 and number of handoff means for network priority multicriteria is 11 .

Conventional method vertical handover decision creates larger number of handoffs, and this may lead to additional signalling load on the network. Mobile priority multicriteria method has the best performance in decreasing the number of handoffs, compared to equal priority and network priority. The weightage of mobile priority multicriteria has a large proportion on mobile speed and traffic class. Mobile speed is linked to the number of handoffs, where mobile users 
TABLE 1: Comparison of vertical handover decision algorithms.

\begin{tabular}{lll}
\hline Heuristic & Advantages & Disadvantages \\
\hline $\begin{array}{l}\text { RSS-based: } \\
\begin{array}{l}\text { Bing et al. [4] } \\
\text { Eshanta et al. [3] }\end{array}\end{array}$ & Low complexity & Low reliability and no user consideration \\
\hline $\begin{array}{l}\text { Multicriteria: } \\
\text { Alkhawlani et al. [21] }\end{array}$ & Low handover failure & No support on fuzzy decision \\
\hline $\begin{array}{l}\text { Context-aware: } \\
\begin{array}{l}\text { Zekri et al. [1] } \\
\text { Hasswa et al. [22] }\end{array}\end{array}$ & High throughput & Additional delay on handover information gathering process \\
$\begin{array}{l}\text { Cost function: } \\
\text { Calvagna and Modica [11] } \\
\text { Ong and Khan [23] }\end{array}$ & High user satisfaction & High complexity \\
\hline $\begin{array}{l}\text { Fuzzy logic: } \\
\text { Ribeiro [14] } \\
\text { Pahlavan et al. [24] }\end{array}$ & High reliability & High complexity \\
\hline
\end{tabular}

TABLE 2: Base station parameter.

\begin{tabular}{lcccc}
\hline Parameter & Unit & WiMAX & WCDMA & WLAN \\
\hline Operating frequency & $\mathrm{MHz}$ & 3500 & 2100 & 2450 \\
Transmitting power & $\mathrm{dBm}$ & 48 & 15 & 20 \\
Antenna gain & $\mathrm{dB}$ & 15 & 6 & 3 \\
Loss (cable, combiner) & $\mathrm{dB}$ & -3 & -3 & -3 \\
EIRP & & 60 & 18 & 20 \\
Path loss & & 160.12 & 118.45 & 139.58 \\
Receiver sensitivity & $\mathrm{dBm}$ & -100 & -100 & -118 \\
Antenna gain & $\mathrm{dB}$ & 3 & 3 & 3 \\
Loss (cable) & $\mathrm{dB}$ & -3 & -3 & -3 \\
Cell radius & $\mathrm{km}$ & 5 & 2.3 & 0.7 \\
Cell edge receiving level & $\mathrm{dB}$ & -100.12 & -100.45 & -119.58 \\
\hline
\end{tabular}

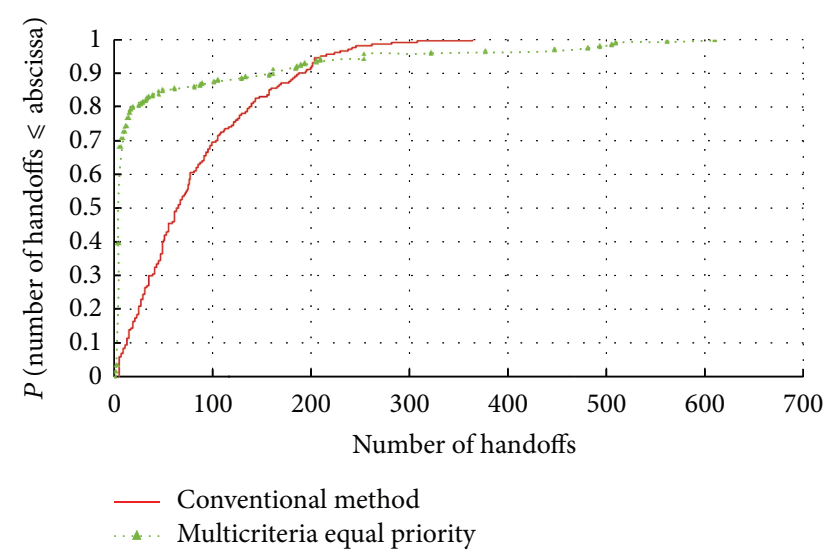

FIGURE 3: Number of handoff distributions of equal priority multicriteria.

with higher speed are more likely to experience ping pong effect. The emphasis of traffic class and mobile speed has successfully diminished unnecessary handovers.

The value of balance index indicates the traffic load balance between different types of network (WLAN, WCDMA, and WiMAX). Figure 6 presents balance index distribution

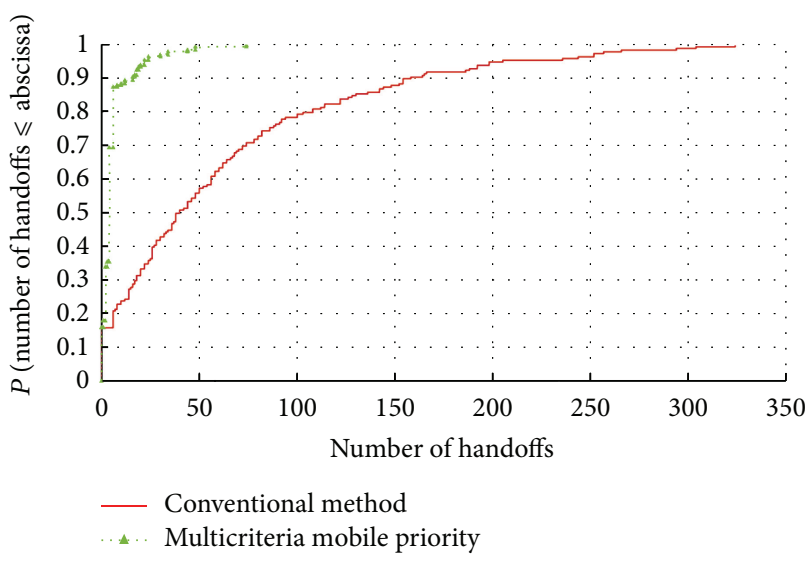

FIGURE 4: Number of handoff distributions of mobile priority multicriteria.

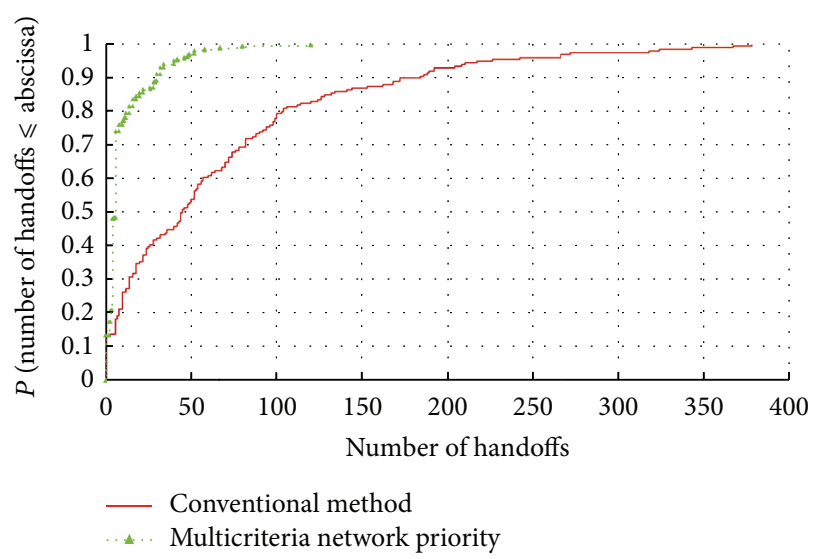

FIGURE 5: Number of handoff distributions of network priority multicriteria.

for equal priority multicriteria. For conventional (RSS-based) method, the mean of balance index is 342.54 . Equal priority multicriteria slightly increased the balance index by $3.66 \%$ to 355.07 . 
TABLE 3: Priority weightage.

\begin{tabular}{lcccc}
\hline Priority type & RSSI & Traffic class & Speed & Network occupancy \\
\hline Equal priority & 0.25 & 0.25 & 0.25 & 0.25 \\
Mobile priority & 0.1 & 0.4 & 0.4 & 0.1 \\
Network priority & 0.1 & 0.1 & 0.1 & 0.7 \\
\hline
\end{tabular}

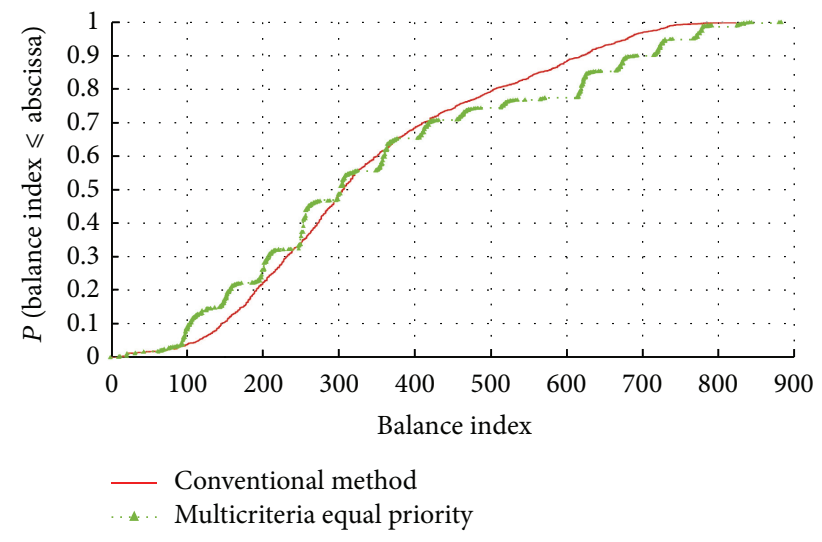

FIgURE 6: Balance index distribution of equal priority multicriteria.

The implementation of mobile priority multicriteria slightly improved the performance of balance index by $0.09 \%$. The mean of balance index of conventional method is 281.04 and the mean of balance index for mobile priority multicriteria method is 280.78 . The distribution of balance index for mobile priority multicriteria is presented in Figure 7.

Balance index is not improved by the implementation of equal priority or mobile priority multicriteria method. In equal priority, weight proportion of the network criterion (network occupancy) is equal to other criteria (RSSI, traffic type, and speed class); meanwhile in mobile priority it emphasized the weight on mobile criteria (traffic type and speed class). Balance index is a network-related performance metric; thus larger proportion of network criterion should be given to improve the balance index.

Network priority multicriteria improved the balance index by $18.03 \%$. The mean of balance index for conventional method is 219.43 and the mean of balance index for network priority multicriteria method is $179.87 \%$. The balance index distribution of network priority multicriteria is presented in Figure 8.

Figure 9 presents the distribution of average blocking probability for equal priority multicriteria method. Blocking probability is a fundamental performance metric because it indicates the ability of the network to serve incoming mobile users. However, equal priority multicriteria degraded the average blocking probability by $7.05 \%$. The mean of average blocking probability for conventional method is 0.12 and the mean of average blocking probability for equal priority multicriteria is 0.13 . Equal priority has equal proportion for all criteria (mobile criteria and network criteria); meanwhile blocking probability is closely related to the network. Larger proportion of network occupancy should be given to improve blocking probability.

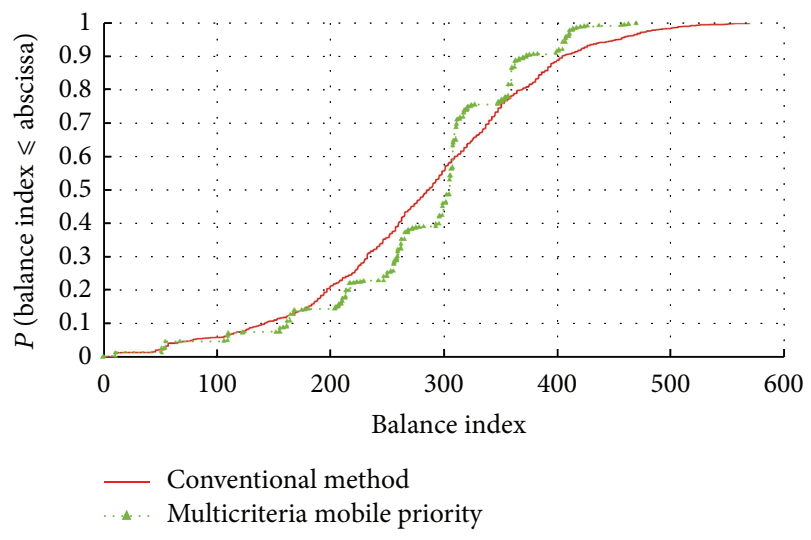

FIGURE 7: Balance index distribution of mobile priority multicriteria.

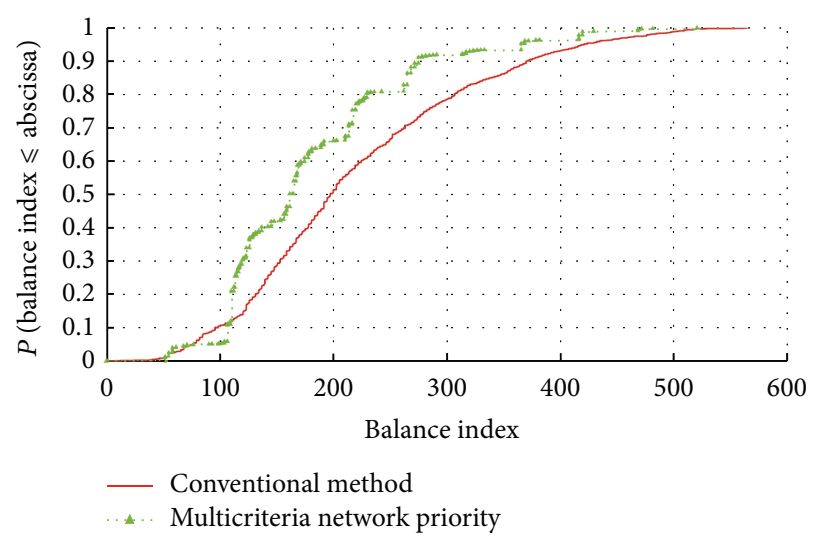

FIGURE 8: Balance index distribution of network priority multicriteria.

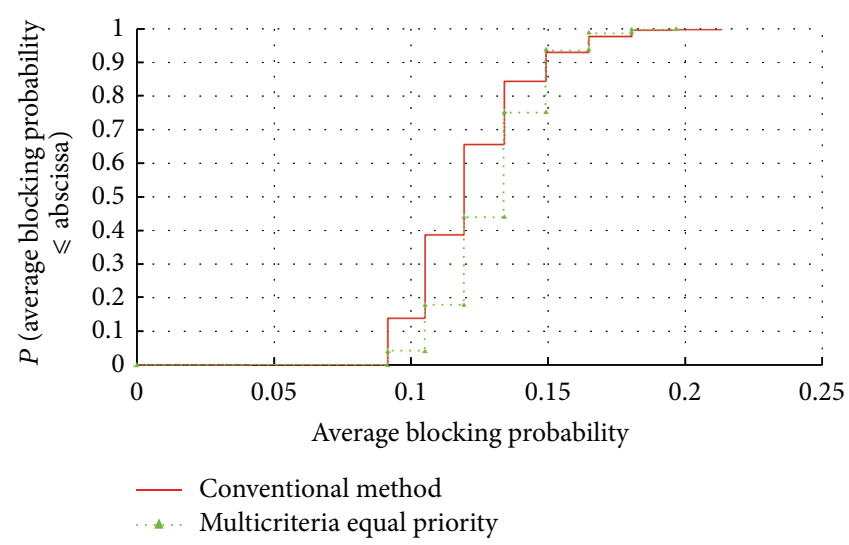

FIGURE 9: Average blocking probability distribution of equal priority multicriteria. 
TABLE 4: Performance improvement comparisons.

\begin{tabular}{lccc}
\hline Performance improvement (\%) & $\begin{array}{c}\text { Equal priority } \\
\text { Multicriteria versus } \\
\text { conventional method }\end{array}$ & $\begin{array}{c}\text { Mobile priority } \\
\text { Multicriteria versus } \\
\text { conventional method }\end{array}$ & $\begin{array}{c}\text { Network priority } \\
\text { Multicriteria versus } \\
\text { conventional method }\end{array}$ \\
\hline Number of handoffs & 46.60 & 90.41 & 84.60 \\
Balance index & -3.66 & 0.09 & 18.03 \\
Average blocking probability & -7.05 & -8.69 & 20.23 \\
\hline
\end{tabular}

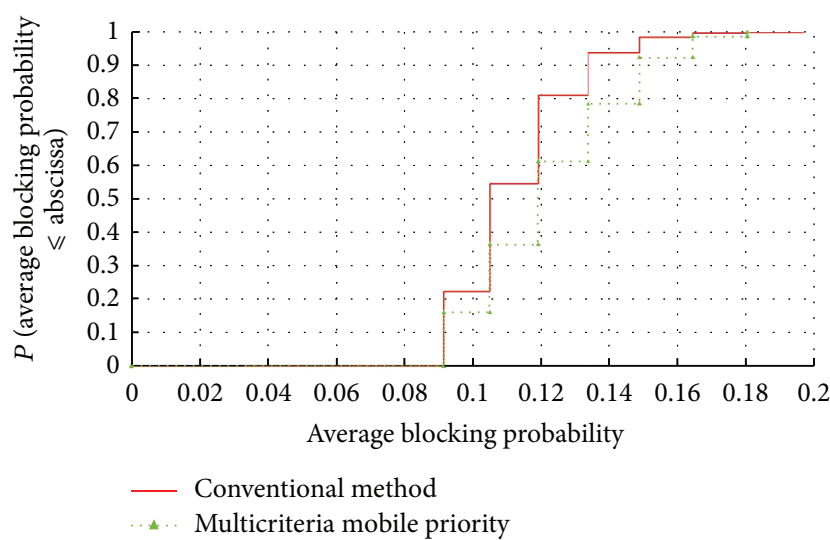

FIGURE 10: Average blocking probability distribution of mobile priority multicriteria.

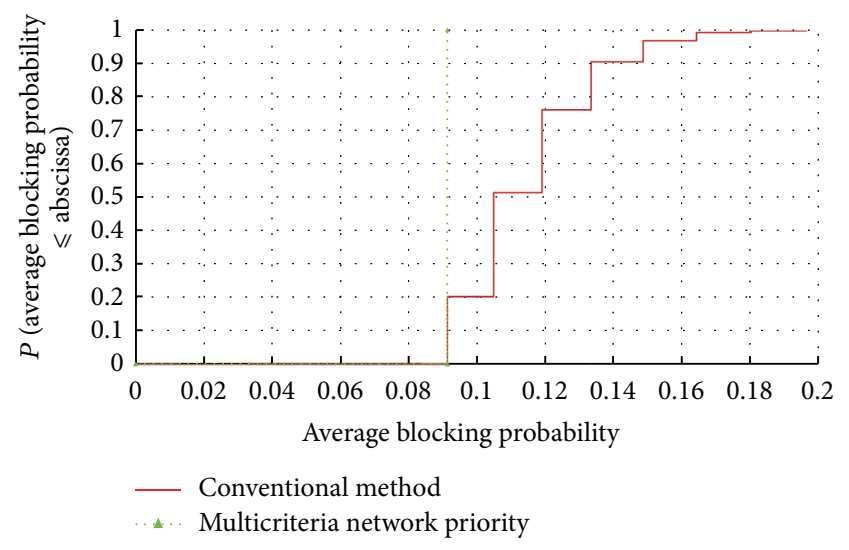

FIGURE 11: Average blocking probability distribution of network priority multicriteria.

In the same way, mobile priority multicriteria also degrade blocking probability. Mean value of average blocking probability increased by $8.69 \%$. Mean value for conventional method is 0.11 and 0.12 for mobile priority multicriteria method. The distribution is presented in Figure 10.

Unlike equal priority and mobile priority, network priority multicriteria significantly improved average blocking probability by $20.23 \%$. Mean value of average blocking probability for conventional method is 0.11 ; meanwhile mean value of average blocking probability for network priority multicriteria method is 0.09 . Average blocking probability is linked to network occupancy, and, in network priority multicriteria method, the weightage of network occupancy is higher compared to other criteria (RSSI, traffic type, and speed class); thus, it successfully reduced the average blocking probability. Table 4 presents performance improvement for all multicriteria methods and performance metrics.

\section{Conclusion and Future Works}

Compared to equal priority and mobile priority, network priority multicriteria vertical handover decision algorithm has improved network performance in terms of number of handoffs, network balance, and average blocking probability. The number of handoffs decreased by $84.60 \%$, while network balance is improved by $20.23 \%$ and average blocking probability improved by $20.23 \%$ compared to conventional method. Generally, network priority multicriteria method has the best performance of balance index and average blocking probability compared to equal priority and mobile priority.

In future works, vertical handover algorithms are to be optimized by combining multicriteria method with other vertical handover methods, such as cost function or fuzzy logic. The combination of multiple strategies will improve network performance.

\section{Conflict of Interests}

The authors declare that there is no conflict of interests regarding the publication of this paper.

\section{Acknowledgment}

The paper research is supported by the Malaysian Ministry of Higher Education under Research Grant no. LRGS/ TD/2011/UKM/ICT/02/02.

\section{References}

[1] M. Zekri, B. Jouaber, and D. Zeghlache, "Context aware vertical handover decision making in heterogeneous wireless networks," in Proceedings of the 35th IEEE Conference on Local Computer Networks (LCN '10), pp. 764-768, Denver, Colo, USA, October 2010.

[2] X. Yan, Y. A. Sekercioglu, and S. Narayanan, "A survey of vertical handover decision algorithms in Fourth Generation heterogeneous wireless networks," Computer Networks, vol. 54, no. 11, pp. 1848-1863, 2010.

[3] O. M. Eshanta, M. Ismail, K. Jumari, and P. Yahaya, "VHO Strategy for QoS-provisioning in the WiMAX/WLAN interworking system," Asian Journal of Applied Sciences, vol. 2, no. 6, pp. 511520, 2009. 
[4] H. Bing, C. He, and L. Jiang, "Performance analysis of vertical handover in a UMTS-WLAN integrated network," in Proceedings of the 14th IEEE International Symposium on Personal, Indoor and Mobile Radio Communications (PIMRC '03), pp. 187191, September 2003.

[5] W. T. Chen, J. C. Liu, and H. K. Huang, "An adaptive scheme for vertical handoff in wireless overlay networks," in Proceedings of the 10th International Conference on Parallel and Distributed Systems (ICPADS '04), pp. 541-548, July 2004.

[6] M. Liu, Z.-C. Li, X.-B. Guo, and H.-Y. Lach, "Design and evaluation of vertical handoff decision algorithm in heterogeneous wireless networks," in Proceedings of the 14th IEEE International Conference on Networks (ICON '06), pp. 1-6, IEEE, Singapore, September 2006.

[7] Q. Wei, K. Farkas, C. Prehofer, P. Mendes, and B. Plattner, "Context-aware handover using active network technology," Computer Networks, vol. 50, no. 15, pp. 2855-2872, 2006.

[8] A. K. Dey and G. D. Abowd, "Towards a better understanding of context and context-awareness," in Proceedings of the 1st International Symposium on Handheld and Ubiquitous Computing, pp. 1-12, 1999.

[9] N. Ryan, J. Pascoe, and D. Morse, "Enhanced reality fieldwork: the context-aware archaeological assistant," in Proceedings of the 25th Anniversary Conference on the Computer Applications and Quantitative Methods in Archaeology (CAA '97), vol. 750 of BAR International Series, pp. 269-274, University of Birmingham, April 1997.

[10] H.-D. Chu, H. Kim, and S.-J. Seok, "Flow based 3G/WLAN vertical handover scheme using MIH model," in Proceedings of the 27th International Conference on Information Networking (ICOIN '13), pp. 658-663, Bangkok, Thailand, January 2013.

[11] A. Calvagna and G. D. Modica, "A user-centric analysis of vertical handovers," in Proceedings of the 2nd ACM International Workshop on Wireless Mobile Applications and Services on WLAN Hotspots, pp. 137-146, 2004.

[12] F. Zhu and J. McNair, "Optimizations for vertical handoff decision algorithms," in Proceedings of the IEEE Wireless Communications and Networking Conference (WCNC '04), pp. 867872, Atlanta, Ga, USA, March 2004.

[13] M. Kassar, B. Kervella, and G. Pujolle, "An overview of vertical handover decision strategies in heterogeneous wireless networks," Computer Communications, vol. 31, no. 10, pp. 26072620, 2008.

[14] R. A. Ribeiro, "Fuzzy multiple attribute decision making: a review and new preference elicitation techniques," Fuzzy Sets and Systems, vol. 78, no. 2, pp. 155-181, 1996.

[15] C. C. Hung and L. H. Chen, "A fuzzy TOPSIS decision making model with entropy weight under intuitionistic fuzzy environment," in Proceedings of the International MultiConference of Engineers and Computer Scientists, pp. 1-4, Hong Kong, 2009.

[16] I. Chamodrakas and D. Martakos, "A utility-based fuzzy TOPSIS method for energy efficient network selection in heterogeneous wireless networks," Applied Soft Computing, vol. 12, no. 7, pp. 1929-1938, 2012.

[17] D. Manjaiah and P. Payaswini, "A review of vertical handoff algorithms based on multi attribute decision method," International Journal of Advanced Research in Computer Engineering and Technology, vol. 2, pp. 2005-2008, 2013.

[18] E. Stevens-Navarro and V. W. S. Wong, "Comparison between vertical handoff decision algorithms for heterogeneous wireless networks," in Proceedings of the 63rd IEEE Vehicular Technology
Conference (VTC '06), pp. 947-951, Melbourne, Australia, July 2006.

[19] K. Savitha and C. Chandrasekar, "Vertical handover decision schemes using SAW and WPM for network selection in heterogeneous wireless networks," Global Journal of Computer Science and Technology, vol. 11, pp. 19-24, 2011.

[20] A. Ismail and R. Byeong-hee, "Adaptive handovers in heterogeneous networks using fuzzy MADM," in Proceedings of the International Conference on Mobile IT-Convergence (ICMIC '11), pp. 99-104, September 2011.

[21] M. M. Alkhawlani, K. A. Alsalem, and A. A. Hussein, "Multicriteria vertical handover by TOPSIS and fuzzy logic," in Proceedings of the International Conference on Communications and Information Technology (ICCIT '11), pp. 96-102, 2011.

[22] A. Hasswa, N. Nasser, and H. Hassanein, "Tramcar: a contextaware cross-layer architecture for next generation heterogeneous wireless networks," in Proceedings of the IEEE International Conference on Communications (ICC '06), pp. 240-245, July 2006.

[23] E. H. Ong and J. Y. Khan, "On optimal network selection in a dynamic multi-RAT environment," IEEE Communications Letters, vol. 14, no. 3, pp. 217-219, 2010.

[24] K. Pahlavan, P. Krishnamurthy, A. Hatami et al., "Handoff in hybrid mobile data networks," IEEE Personal Communications, vol. 7, no. 2, pp. 34-47, 2000.

[25] K. Staniec, M. J. Grzybkowski, and K. Erlebach, "Propagation modeling," in Understanding UMTS Radio Network Modelling, Planning and Automated Optimisation Theory and Practice, M. J. Nawrocki, M. Dohler, and A. H. Aghvami, Eds., pp. 69-113, John Wiley \& Sons, West Sussex, UK, 1st edition, 2006.

[26] S. Zvanovec, P. Pechac, and M. Klepal, "Wireless LAN networks design: site survey or propagation modeling?" Radioengineering, vol. 2, pp. 42-49, 2003.

[27] T. Casey, D. Denieffe, and G. M. Muntean, "Influence of mobile user velocity on data transfer in a multi-network wireless environment," in Proceedings of the 9th IFIP International Conference on Mobile Wireless Communications Networks, pp. 126-130, 2007.

[28] C. Hebbi and S. V. Saboji, "Vertical handoff in heterogeneous wireless mobile networks," in Proceedings of the 1st International Conference on Networks and Communications (NetCoM '09), pp. 66-71, IEEE, Chennai, India, December 2009.

[29] H. Velayos, V. Aleo, and G. Karlsson, "Load balancing in overlapping wireless LAN cells," in Proceedings of the IEEE International Conference on Communications, pp. 3833-3836, June 2004.

[30] V. B. Iversen, Teletraffic Engineering and Network Planning, 1st edition, 2004. 

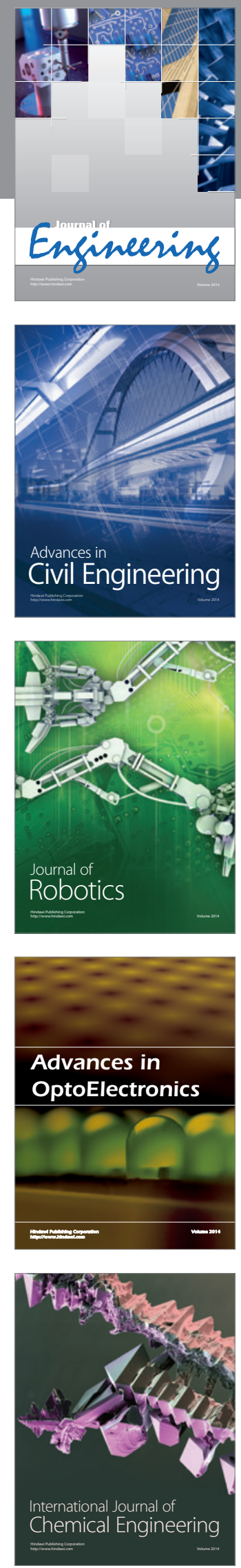

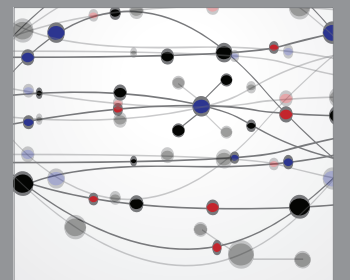

The Scientific World Journal
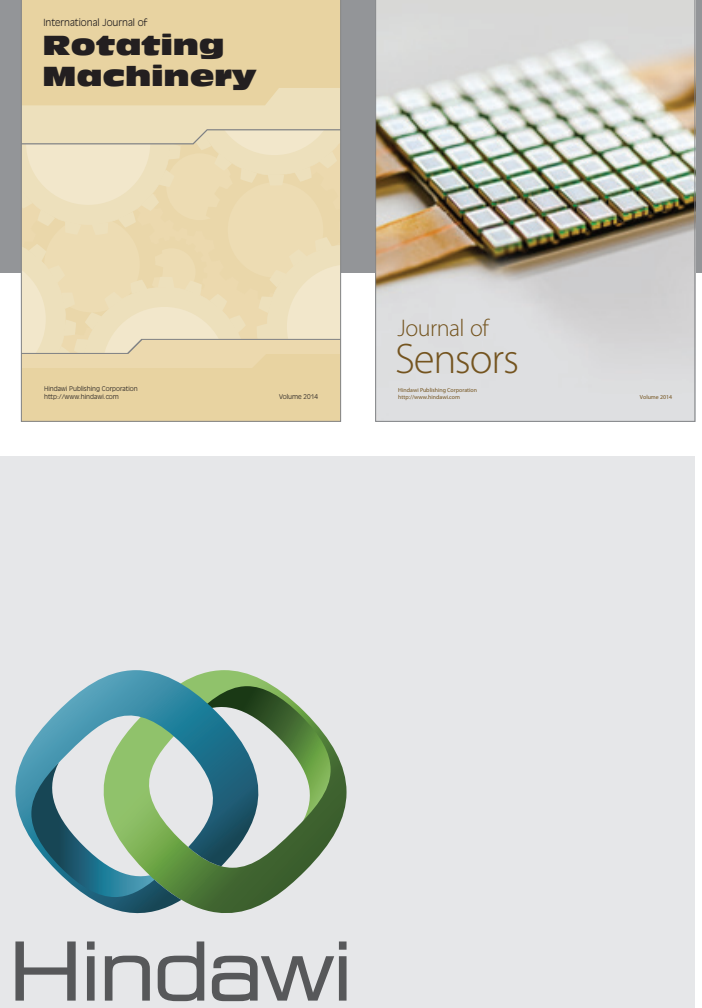

Submit your manuscripts at http://www.hindawi.com
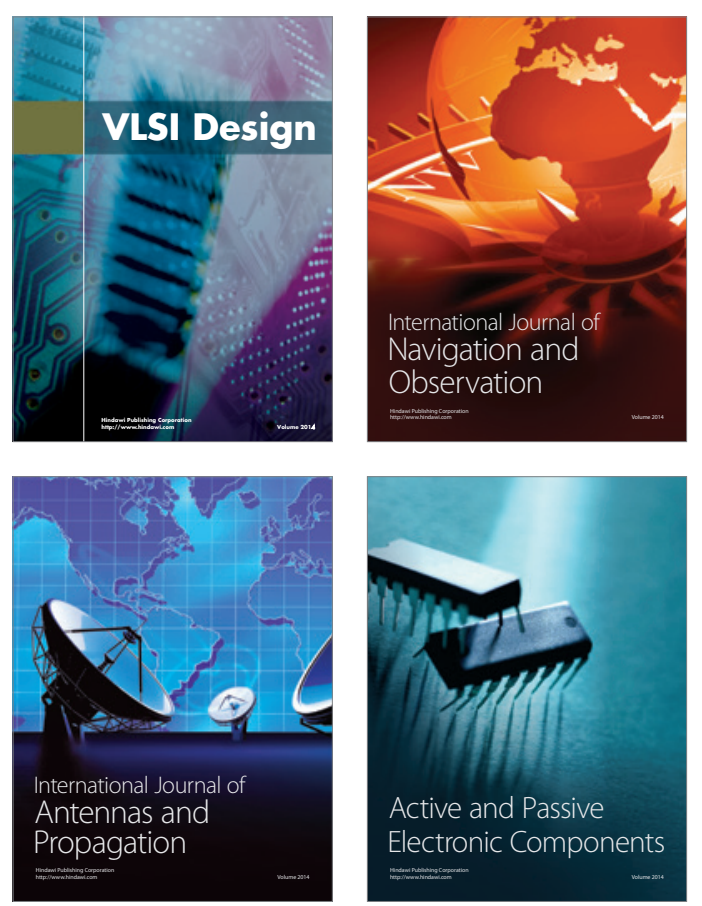
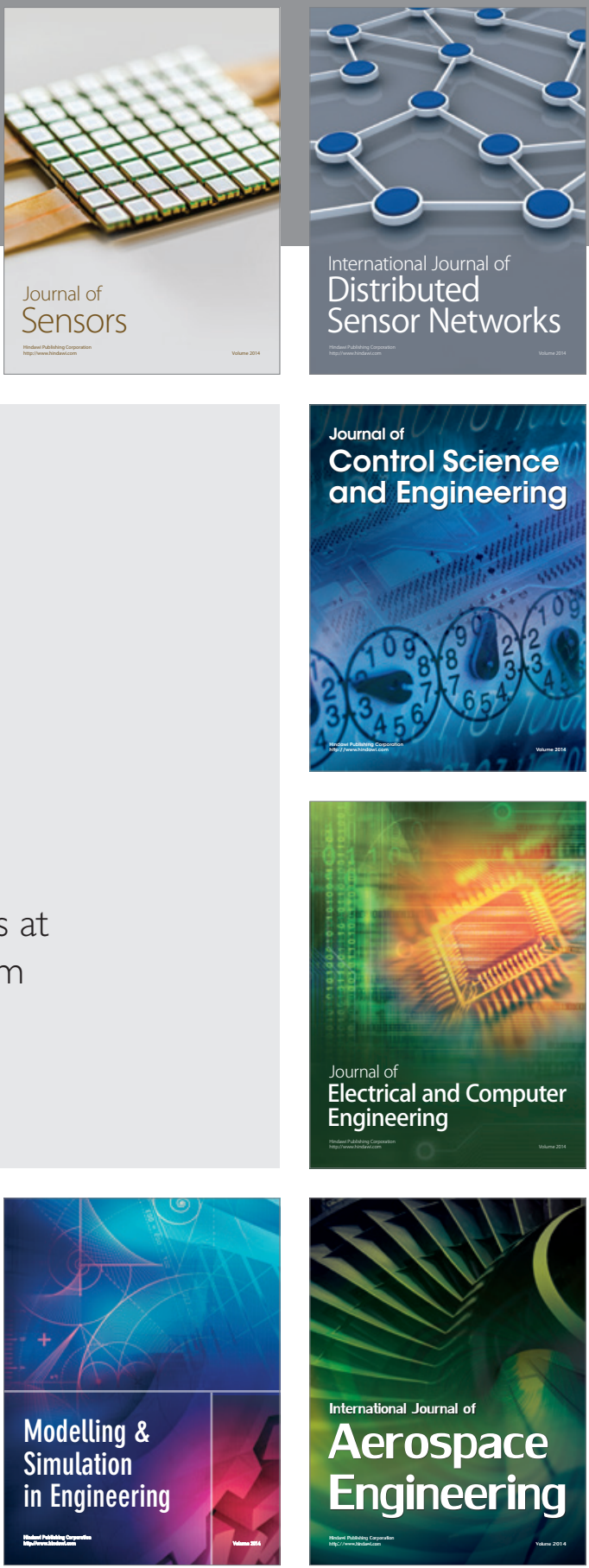

Journal of

Control Science

and Engineering
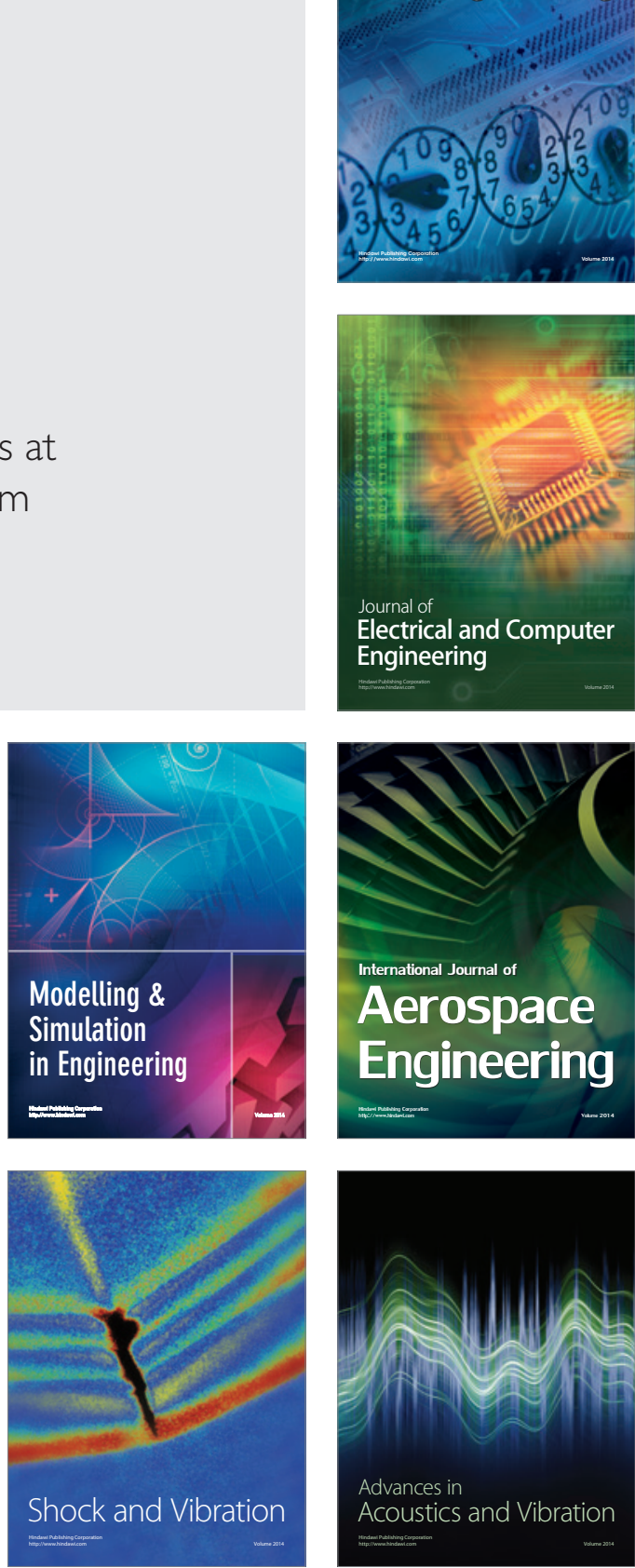